\title{
Capacity and Concessions: Bargaining Power in Multilateral Negotiations
}

Gerald Schneider

\begin{abstract}
Realism and liberalism disagree over the source of bargaining power in international relations. Realists believe that the success of a negotiator is a linear function of the capabilities that its home state possesses. Liberals stress the crucial importance of either the relative salience a country attaches to a contested issue or the importance negotiating governments have to attribute to powerful domestic actors. In this essay, I clarify some of the channels through which these different facets of power influence multilateral negotiations. To examine the competing theoretical claims in international negotiations, I rely on the canonical contribution to the formal theory of bargaining, the Nash Bargaining Solution (NBS), as the unifying analytical framework. I $h$ several causal mechanisms through which varying forms of resources affect the negotiation outcomes. The formal analysis points out severe limitations of the thesis that different forms of bargaining power are fungible. Whether different facets of power can be substituted at all depends on how specific a channel is through which power is exerted. The empirical application uses the saliency approach as the baseline model and compares it with a realist capability and a liberalist domestic politics model. The analysis of the Uruguay round negotiations in the tourism sector shows that the realist bargaining model outperforms the domestic politics model. The saliency version of the NBS on which the competing models are based also fares relatively well in forecasting the concessions that 29 member states made in this policy realm.
\end{abstract}

'Well, either side could win it, or it could be a draw.'

Ron Atkinson, English football pundit

In July 2004, Japan threatened to leave the International Whaling Commission by 2006 if it were not satisfied with the performance of that international organisation by this time. As any diplomatic historian could easily confirm, the usage of such stratagems is frequent in world politics. Yet, political leaders do not always have to issue explicit threats 
- or their functional equivalent, promises - to reach the outcome they prefer. In some situations, the claim of a resourceful state easily convinces hesitating actors that they had better give in and accept what amounts to a second-best solution for them. The not-so-veiled hint 'we want our money back' with which Prime Minister Thatcher started her 'career' in the European Union was, in the beginning at least, a sufficient tactic. It convinced the more cooperation minded governments that concessions to the recalcitrant British Prime Minister were a necessary evil to move the course of integration forward. The threat that the new member state could leave the organization again was indirect at best, but clearly understood by the other members. ${ }^{1}$

These contrasting examples easily show that international negotiations take many forms. In some cases, an actor just has to be present at the negotiation table to receive what it wants. Yet, in other situations a remark about what would happen if the demands are not fulfilled has to accompany the claim. Such maneuvers do not have to entirely verbal. States which rely on "tacit bargaining" try to coerce other states through troop movements and similar steps into the acceptance of some demands. ${ }^{2}$

Bargaining is, in my view, also much more prevalent in world politics than alternative interaction modes such as fighting, voting or delegation. As some neo-Clausewitzans maintain, war is another form of bargaining which informs the contestants about the relative power and resolve of the other side. ${ }^{3}$ Before an international organization votes on a particular issue, its member states have been negotiating on the possible compromise for a long time. This renders the final decision

This article continues joint work with Stefanie Bailer, Konstantin Baltz and Daniel Finke on bargaining power in the European Union. I would like to thank the Volkswagen Foundation and the European Commission under the 6th Framework Program (Project CIT-2-CT-2004-506084) for funding, and Daniel Finke for his help in calculating the bargaining solutions and for commenting upon the draft version of this article. The comments of two anonymous reviewers were extremely helpful. The accompanying GAUSS routines that have been used to calculate the model predictions are available at the homepage of the author: http: / / www.unikonstanz.de/FuF/Verwiss/GSchneider/downloads/daten.htm.

1. Gerald Schneider and Lars-Erik Cederman, 'The Change of Tide in Political Cooperation: A Limited Information Model of European Integration', International Organization 48 (1994): 633-62.

2. George W. Downs and David M. Rocke, Tacit Bargaining, Arms Races and Arms Control (Ann Arbor: University of Michigan Press, 1990).

3. Robert Powell, 'Bargaining Theory and International Conflict', Annual Review of Political Science 5 (2002): 1-30. 
largely symbolic. Although much of the operational work in international affairs is delegated to bureaucracies and international organizations, the exact content of these obligations has been decided beforehand in negotiations.

Although bargaining is thus prevalent in almost any international interaction, we hardly know how one of its key determinants - power - affects negotiation outcomes. In part, this situation is just a reflection of a general weakness in the international relations literature. As Nye famously quipped: 'Power in international politics is like the weather. Everyone talks about it, but few understand it'. $^{4}$ Nonetheless, our limited comprehension of just how power influences negotiation processes is still puzzling given that the dispute over the function of capabilities and other facets of power enjoys a long and distinguished tradition in the history of international relations theory. Realists have typically maintained that a state's leverage in the international system is a positive and linear function of its capabilities. This holds especially true for classical deterrence theory, which posits a positive relationship between the capabilities of the defender and the probability of deterrence success. ${ }^{5}$ The capability-thesis, of course, is not limited to realism. In his famous treatise on economic statecraft, development theorist Hirschman similarly asserted that the resources of an actor influence the relative attractiveness of an alternative to an agreement. ${ }^{6}$

Some liberals, on the other hand, maintain that individual success - how small the own concessions are in comparison to the concessions of other actors - at the bargaining table is inversely linked to the saliency a negotiator attaches to a contested issue. Identifying "asymmetric interdependence" as the root cause for differences in such evaluations, Keohane and Nye, as well as Moravcsik, ${ }^{7}$ maintain that economically integrated countries will make larger concessions

4. Joseph S. Nye Jr., 'The Changing Nature of World Politics', Political Science Quarterly 105, no. 2 (1990): 177-92.

5. Frank C. Zagare and D. Mark Kilgour, Perfect Deterrence (Cambridge: Cambridge University Press, 2000).

6. Albert O. Hirschman, National Power and the Structure of Foreign Trade (Berkeley: University of California Press, 1980).

7. Robert O. Keohane and Joseph. S. Nye Jr., Power and Interdependence (Boston: Little, Brown, 1977).

8. Andrew Moravcsik, The Choice for Europe: Social Purpose and State Power from Messina to Maastricht (Ithaca: Cornell University Press, 1998); and Andrew Moravcsik and Anna Vachudova, 'National Interests, State Power, and EU Enlargement', East European Politics and Societies 17 (2003): 42-57. 
because they anticipate bigger gains. Stefanie Bailer has found support for this proposition in an analysis of the gains and losses that actors made across 162 contested issues within the European Union, noting that 'the urgency that the negotiating member attributes to an issue decreases rather than increases bargaining success'. ${ }^{9}$ Another tradition within liberalism maintains that the negotiation position of a government at the bargaining table largely reflects its need to answer to powerful domestic actors. This is particularly true for the political economy literature that traces the bargaining success of a negotiator back to the influence of powerful domestic actors. ${ }^{10}$ The two-level game literature adds an institutional twist to this preference-based explanation, stressing how formal restrictions that limit the options of a negotiator enhance her influence. ${ }^{11}$ Although evidence supporting this proposition is scant in day-to-day decision making within the European Union, ${ }^{12}$ a limited zone of agreement has repeatedly helped less cooperation-minded leaders in the multilateral summit meetings of the organisation. ${ }^{13}$

In this article, I will integrate the competing claims about the source of bargaining power in international relations into a unifying analytical

9. Stefanie Bailer, 'Bargaining Success in the European Union: The Impact of Exogenous and Endogenous Power Resources', European Union Politics 5, no. 1 (2004): 99-123, 115. See also Stefanie Bailer, Macht und Verhandlungserfolg im Ministerrat der Europäischen Union [Power and Bargaining Success in the Council of Minister of the European Union], unpublished doctoral dissertation, University of Konstanz, 2004.

10. Gerald Schneider and Konstantin Baltz, 'The Power of Specialization: How Interest Groups Influence EU Legislation', Rivista di Politica Economica 93 (January-February 2003): 253-83.

11. Thomas C. Schelling, The Strategy of Conflict (Cambridge, MA: Harvard University Press, 1960); Robert D. Putnam, 'Diplomacy and Domestic Politics: The Logic of Two-Level Games', International Organization 42 (1988): 427-60; Keisuke Iida, 'When and How Do Domestic Constraints Matter? Two-Level Games with Uncertainty', Journal of Conflict Resolution 37 no. 3 (1993): 403-26; Schneider and Cederman 'Change of Tide'; and Helen V. Milner, Interests, Institutions, and Information (Princeton: Princeton University Press, 1997).

12. Stefanie Bailer and Gerald Schneider, 'Nash versus Schelling? The Importance of Constraints in Legislative Bargaining', in The European Union Decides, eds. Robert Thomson, Frans N. Stokman, Christopher H. Achen, and Thomas König (Cambridge: Cambridge University Press, forthcoming).

13. Schneider and Cederman, 'Change of Tide'; Simon Hug and Thomas König, 'In View of Ratification, Governmental Preferences and Domestic Constraints at the Amsterdam Intergovernmental Conference', International Organization 56, no. 2 (2002): 447-76. 
framework. The main goal is to clarify how asymmetries in actors' capabilities vs. asymmetries in the salience attached to a negotiation influence the concessions made in a multilateral setting. The Nash Bargaining Solution (NBS), a foundational model within formal bargaining theory, is used to demonstrate a number of causal mechanisms through which asymmetries in the capabilities or saliencies influence international negotiations. Hence, I will clarify how the influence of various facets of power differs according to the channel through which they are exerted. To start with, I will use a model that is inspired by the saliency arguments of Keohane and Nye and many others as the analytical starting point. ${ }^{14}$ I contrast this version of the NBS with two more complex versions: a "realist" NBS model considers the economic might of a country, while a domestic politics model includes information on the relative influence of interest groups at home.

I offer a case study on the Uruguay round negotiations in the early 1990s to bolster my claims. This empirical application refers to the extent to which the participating countries were able to shield their home markets against foreign competitors in tourism. The diagrammatic and mathematical analysis that I offer demonstrates that different forms of bargaining power can offset each other This casts doubts on the fungibility thesis according to which different facets of power can serve as substitutes for each other. ${ }^{15}$ The analysis rather shows that sources of influence can offset each other if they work through competing mechanisms with which an actor tries to influence a negotiation process. In addition, the empirical analysis reveals that the greater the saliency an actor attaches to the negotiation, the smaller the concessions they are likely to win. The economic might of a country partly offsets this influence, while the relative power of domestic stakeholders (here, the tourism sector) is not important on average.

The remainder of the paper is structured as follows: I will first define the key terms and introduce the diverse bargaining models. Next, I will present the research design and the results that I obtained from the evaluation of the competing analytical frameworks. The paper ends with a discussion of how bargaining power relates to other facets of a state's capacity in the international system and how bargaining theory could be used to revise general theories of international relations.

14. Keohane and Nye.

15. Robert Art, 'American Foreign Policy and the Fungibility of Force', Security Studies 5 (1996): 7-42. 


\section{The Baseline Model}

Bargaining is both a cooperative and a conflictive decision-making mode. ${ }^{16}$ The process is cooperative in the sense that all participating actors can improve their situation in comparison to the status quo. Bargaining outcomes are thus Pareto superior because no actor would take part in a negotiation unless they have a reasonable expectation of gain. This is especially true in international politics where agreements typically need unanimous consent.

Bargaining is simultaneously a conflictive endeavour because each actor would like to profit from the negotiations as much as possible and to increase her share of the joint gain to the detriment of the other negotiatiors. The resulting heterogeneity of claims motivates a doubleedged theoretical query: What is the key factor determining the disparity in size and/or amount of the concessions obtained by the different actors in the negotiation process? Does power benefit those able to draw on resources to the detriment of those who are not? The social scientists who try to grapple with these questions tend to fall into two general schools. The first approach stems largely from social psychology, and is, by and large, empiricist. It tries to uncover the negotiation behaviour of individual negotiators and assesses the importance of cognitive failures in international negotiations. A major finding of this school is that education and increased information render it more likely that a negotiator is successful. ${ }^{17}$

This article mainly draws on the second of the two approaches, the formal theory of bargaining. Bargaining theory, which has a rich tradition in economics, political science and international relations, is a branch of game theory. ${ }^{18}$ To explain the function of power in international negotiations, I rely in particular on one of the cornerstones in this branch of game theory - the Nash Bargaining Solution (NBS). John Nash originally developed the NBS for the analysis of bilateral bargaining

16. R. Harrison Wagner, 'Bargaining and Conflict Management', in Multiple Paths to Knowledge in International Relations, eds. Zeev Maoz et al. (Lexington: Lexington Books, 2004), 39-72.

17. For discussions see Max H. Bazerman, Jared R. Curhan, Don A. Moore and Kathleen L. Valley, 'Negotiation', Annual Review of Psychology 51 (2000): 279-314; and Bailer, Macht und Verhandlungserfolg.

18. For recent reviews see Abhinay Muthoo, Bargaining Theory with Applications (Cambridge: Cambridge University Press, 1999); Abhinay Muthoo, 'A NonTechnical Introduction to Bargaining Theory', World Economics 1, no. 2 (2000): 145-66; Robert Powell, 'Bargaining Theory and International Conflict'; and Bailer, Macht und Verhandlungserfolg. 
situations.$^{19}$ One attractive feature of this approach is that it can be easily extended to the analysis of multilateral bargaining contexts.

In its simplest form, the NBS predicts that the players agree on a unique solution in the bargaining space $\Theta$. This feature of the NBS - the uniqueness of the forecasted equilibrium - holds for both bilateral and multilateral negotiations. The predicted agreement maximises the product of the individual utility differences between the actors' disagreement values $\mathrm{Q}$ and an outcome $\mathrm{O}$. The disagreement values stand for the actors' minimum expectation; in other words, there is no incentive to negotiate below this threshold. Equation (1) formalises the multilateral maximisation problem among $\mathrm{n}$ actors:

(1) $\max _{O \in \Theta} \prod_{i=1}^{n}\left(u_{i}(O)-u_{i}(Q)\right)$

Nash's approach is axiomatic. This means that any agreement has to live up to sensible criteria like Pareto efficiency and thus the requirement that a bargaining outcome improves the welfare of the negotiators. Although several authors have criticised some of these axiomatic conditions, recent considerations point out that the solution concept is also compatible with less restrictive approaches. Especially in situations in which the time span between the different bargaining rounds is negligible, the NBS coincides with the most influential dynamic approach in bargaining theory, the Stăhl-Rubinstein sequential bargaining model. ${ }^{20}$ The standard versions of both the NBS and the Ståhl-Rubinstein model rest on the assumption that the participating actors are fully informed about the preferences and power of all negotiating actors. As I lack a convincing theory about the distribution of information in a multilateral setting, I will refrain from relaxing this notion.

19. John F. Nash Jr., 'The Bargaining Problem', Econometrica 18 (1950): 155-62. See also John F. Nash Jr., 'Noncooperative Games', Annals of Mathematics 54 (1951): 289-95; and John F. Nash Jr., 'Two-person Cooperative Games', Econometrica 21 (1953): 128-40.

20. Kenneth Binmore, Ariel Rubinstein and Asher Wolinsky, 'The Nash Bargaining Solution in Economic Modeling', RAND Journal of Economics 117 (1986): 176-88. See also Ariel Rubinstein and Martin J. Osborne, Bargaining and Markets (New York: Academic Press, 1990); and Ariel Rubinstein 'Perfect Equilibrium in a Bargaining Model', Econometrica 50 (1982): 97-110. 


\section{The Definition of Power}

I will illustrate some of the channels through which power can affect bargaining situations with the help of a bilateral bargaining situation. The conception of power I rely on is Weberian: actors are powerful if they possess some capacity to withstand pressure or, to put it the other way around, to force other actors to give in. Knight advances a similar perspective, writing: 'To exercise power over someone or some group is to affect by some means the alternatives available to that person or group'.$^{21}$ In a bargaining situation, power finds its empirical expression in the concessions that an actor makes or, more loosely speaking, the 'influence' that the negotiation partner exerts.

To assess the consequences of power requires counterfactual reasoning. We thus see the effect of bargaining power if a negotiator yields more in real negotiations with unequal power distribution than he or she would in the counterfactual confrontation in which a balance of power is maintained. In other words, a successful power play results in a disproportionate division of spoils, which reflects the unequal prior distribution of resources or other facets of power. Note that my definition of bargaining power, which links diverse facets of power to concessions at the negotiation table, is in line with the position of some voting power theorists. One of the key controversies in this literature dates back to Barry's useful dinstinction between "power" and "luck". Accordingly, to have a preference which is similar to the final outcome of a decision making process can be a coincidence rather than a manifestation of power. ${ }^{22}$ Hence, to define power through the bargaining position of an actor can be misleading. Braham and Holler have recently put forward a similar argument and claimed that power is 'a generic ability because it involves the capacity to do things that have an effect'. ${ }^{23}$ In a critique of Napel and Widgrén' $\mathrm{s}^{24}$ attempt to develop preference-based voting power indices, they stress that power measures must, however, exclude a reference to the preference of an actor.

21. Jack S. Knight, Institutions and Social Conflict (Cambridge: Cambridge niversity Press, 1994), 41.

22. Brian Barry 'Is It Better to Be Powerful or Lucky?: Part 1' , Political Studies 28 (1980): 183-194 and Brian Barry 'Is It Better to Be Powerful or Lucky?: Part 2', Political Studies 28 (1980): 338-352.

23. Matthew Braham and Manfred J. Holler, 'The Impossiblity of a PreferenceBased Power Index', Journal of Theoretical Politics 17 (2005): 137-157, 145, emphasis in original.

24. Stefan Napel and Mika Widgrén, 'Power Measurement as Sensitivity Analysis: A Unified Approach', Journal of Theoretical Politics 16 (2004): 517-538. 
Before I deal with the measurement of power and influence, I will discuss the mechanisms through which the capacity of the negotiators affects the concessions they make at the bargaining table. The following discussion is limited to some of the means that a powerful actor might use in a negotiation. These are: the manipulation of the 'outside option', the importance or 'saliency' attached to a bargain, and the use of greater capabilities as a negotiation tool. Muthoo's excellent essay has shown how actors can also profit from information asymmetries and different levels of impatience (i.e. varying discount rates for the future consumption of the individual share of the spoils)..$^{25}$ Østerdal further demonstrates that asymmetric capabilities also affect the outcomes in repeated encounters between the same actors through the one-sided reduction of the possible courses of action which the negotiators pursue. ${ }^{26}$ In his original contribution, Nash assumed such differences away, qualifying the actors as equally skillful and time as unimportant. ${ }^{27}$ The simultaneous offer framework of the NBS also prevents the analyst from studying how threats and other "non-cooperative" moves can lead to inefficient outcomes. ${ }^{28}$

To explore the function of the facets of power that international relations theories are concerned with, the NBS is, however, an appropriate analytical tool. Standard approaches like liberalism and realism are most often static and thus do not specify the temporal order

25. Muthoo, 'Non-Technical Introduction'.

26. Lars Peter Østerdal, 'Bargaining Power in Repeated Games', Mathematical Social Sciences 49 (2005): 101-110.

27. Nash, 'The Bargaining Problem'. Daniel Finke, Stefanie Bailer and I have compared a multilateral Ståhl-Rubinstein model with NBS models that consider the votes a country has in the Council of Ministers and found that time preference models have the highest average predictive accuracy, while capability-based models fare well in predicting the outcome perfectly (point predictions). Schneider, Finke and Bailer, 'Bargaining Power in the European Union: An Evaluation of Competing Game-Theoretic Model', unpublished working paper, University of Konstanz, 2004.

28. The NBS belongs to the cooperative branch of game theory and thus assumes that actors have agreed on the way in which they interact. Pre-play interactions are thus considered to be unimportant. Non-cooperative game theory, to which Nash also made the inaugural pioneering contribution, models all steps that are important for understanding a social interaction and thus also the unilateral moves away from the implicity assumed agreement on how a game is played in the world of cooperative game theory. As indicated, the NBS with the non-cooperative sequential bargaining game of Ståhl-Rubinstain under the proviso that the time interval between the offers of the bargainers is negligible (Binmore at al. 'The Nash Bargaining Solution in Economic Modeling'). 
in which different actors try to influence each other. A non-dynamic model like the NBS is ideally suited to test the implications that these general theories have for our understanding of bargaining power. Furthermore, compared to some other modeling approaches, the NBS possesses considerable forecasting power and is amenable to empirical research. ${ }^{29}$ It relies on concepts that are measurable; non-cooperative models, by contrast, often use highly abstract variables like "asymmetric information" that are hard to assess in a non-experimental setting.

\section{The Credibility of a Commitment}

Figure 1 summarises a situation in which actors A and $B$ divide $1 €$. The set of feasible outcomes - the so-called bargaining space - is the triangle linking the origin and the two extreme outcomes in which one side receives everything and the other side nothing. The line that connects these two 'dictator' solutions is the Pareto frontier. The origin stands for a situation where the actors' disagreement points amount to zero. This means that they would accept any bargain that gives them at least this outcome.

Figure 1: The Effects of Outside Options in Bilateral Situations

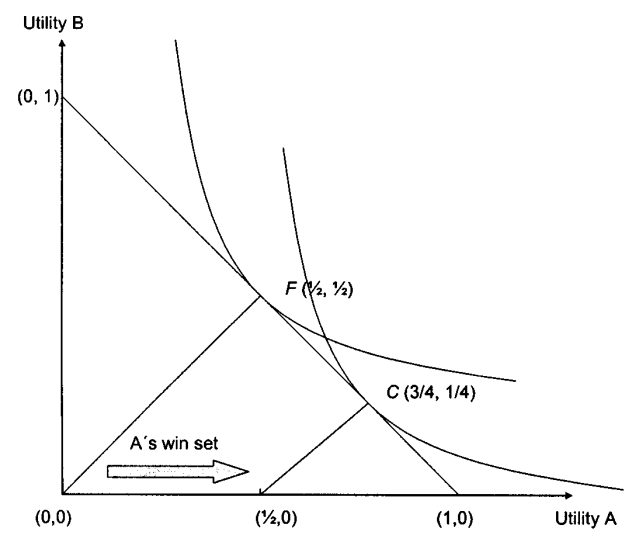

The analytical attraction of the NBS is that it predicts a unique outcome on the Pareto frontier as a solution to the bargaining process. In the event that the actors are equally powerful, this forecast coincides with the fair

29. Christopher H. Achen, 'Institutional Realism and Bargaining Models ', in The European Union Decides. 
division result where each side receives 50 cents. To see why this is the case, we simply have to optimise the product of the differences between the preferences and the disagreement values, i. e., o(1-o). This leads to 1$2 \mathrm{o}=0$ or $\mathrm{o}=1 / 2$. In Figure 1 , the outcome $F$, where the indifference curve touches the Pareto frontier, stands for this solution.

A first possibility in which bargaining power can shift the outcome away from $\mathrm{F}$ arises when one negotiator possesses a better 'outside option $^{\prime 30}$ and thus attributes a higher gain to disagreement than does the other negotiator. The example described in Figure 1 illustrates this causal mechanism through a shift of the disagreement point of actor A to $1 / 2$. In this situation, the 'zone of agreement' - or, in Putnam's wording, the 'win set' - of actor A becomes smaller. ${ }^{31}$ This unequal distribution of bargaining power benefits $\mathrm{A}$, as the unique prediction of the NBS will now be outcome $C$ where A receives 75 cents and B only 25 cents. We can quickly see why this is the case when we maximise (o$0.5)(1-0)$, which leads to $\mathrm{o}=0.75$. The theoretical implication of this is that actors who possess a more attractive 'outside option' can credibly claim that their wishes have to be respected. They will accordingly receive the larger share of the spoils in comparison to actors who are deprived of the possibility to commit themselves to a particular outcome. . $^{32}$

It was Schelling who first brought to prominence the insight that the success of a negotiator largely depends on the attractiveness of an outside option. ${ }^{33}$ His famous 'paradox of power' even leads to to the expectation that the actor with less resources might receive a greater piece of a pie than the more 'powerful' one. Thus Schelling argued that governments which face a strong opposition back home and are thus less 'powerful' can more easily convince the other side that only a minimal agreement is feasible; their commitment is more credible

30. The "outside option" is equivalent to what game theorists also call the reference point of an actor. It reflects the temporary outcome that results in case of disagreement and often - but not always - corresponds to the status quo. If actors value the minimal expectation they have in a bargain equally as the outside option, we can also conceive of it as the so-called "reservation price". For further categorizations of alternatives that may result in case of permanent or temporary disagreement of negotiators see Muthoo, Bargaining Theory with Applications.

31. Putnam

32. Muthoo, Bargaining Theory with Applications and 'A Non-Technical Introduction'.

33. Schelling. 
precisely because they are powerless to do otherwise. Putnam popularised this conception with the notion of 'two-level games' and maintained that ratification constraints are important power resources. ${ }^{34}$ The empirical evidence on the 'Schelling' conjecture is, however, mixed. While severe ratification constraints are important in the negotiations among the heads of governments of the European Union member states, ${ }^{35}$ no such relationship exists for the interactions in the Council of Ministers. ${ }^{36}$ Others have nearly gone as far as dismissing the empirical evidence of the so-called Schelling conjecture entirely. ${ }^{37}$ In this essay, I will largely focus on how two other power mechanisms - resources and the saliency attached to a bargain - affect the final outcome.

\section{Resources}

The 'paradox of power' was initially a response to the widespread belief that only capabilities shape an actor's influence at the negotiation table. Guided by this belief, many realists have speculated about the forms of power which increase the bargaining leverage of a negotiator. Resources upon which a negotiator can draw are traditionally thought to include the size of the economy, armed forces, or the overall population of a country. As Nye has shown, 'soft' forms of power - such as information or culture- complement this list. ${ }^{38}$ However, as the number of possible capability indicators grows, so does the problem of indeterminacy. Since an imaginative researcher can always find an indicator that correlates with success, statements that 'power' was decisive are often post hoc.

This theoretical quandary has, however, not deterred scholars from claiming that capabilities foster the bargaining success of negotiators. A typical statement along this line of reasoning is Art's qualification of the advantages of armament: "militarily powerful states have greater clout in world politics than militarily weak ones". ${ }^{39}$ Over the past few decades, scholars as diverse as Hirschman and Knorr have

\section{Putnam.}

35. Schneider and Cederman, 'Change of Tide'; and Hug and König, 'In View of Ratification'.

36. Bailer, Schneider, 'Nash versus Schelling?'

37. Thomas Hammond and Brandon C. Prins, 'Domestic Veto Institutions, International Negotiations, and the Status Quo: A Spatial Model of Two-Level Games with Complete Information', unpublished working paper, Michigan State University, 1998; and Milner, Interests, Institutions, and Information. Stefanie Bailer and I discuss this controversy at length in 'Nash vs. Schelling'.

38. Nye, 'Changing Nature'.

39. Art, 16. 
advanced similar hypotheses. ${ }^{40}$ Apart from the fact that such a direct source of power drives only one of the causal mechanisms that bargaining theory suggests, the analytical problem with such reasoning is of course that it is overly simplistic; that is, it associates a state's capacity with its bargaining advantage mainly in a linear fashion. The lack of a functional form that explicitly links capacity to bargaining success becomes clear through Hirschman's statement that 'superior bargaining power enables one monopolist ...to increase his gain at the expense of that of his partner'. ${ }^{41}$

The NBS, however, connects power to a disproportional division of the spoils in a different fashion. It relies on a non-linear functional form; capabilities enter this model as an exponential weight in the utility function of the individual actor. Hence, the inclusion of the capability stock $c_{i}$ transforms equation (1) into the following expression:

(2) $\max _{O \in \Theta_{i=1}} \prod_{i}^{n}\left(u_{i}(O)-u_{i}(Q)\right)^{i} \quad$ where $\sum_{i=i}^{n} c_{i}=C$

The substantive meaning of this transformation of equation (1) is that powerful actors can allow themselves to accept more risks than their counterparts with fewer capacities. ${ }^{42}$ By way of illustration, assume that the capabilities of actor A are twice as large as those of actor B. In this case, the maximisation problem boils down to the function $\left(o^{2}\right)(1-o)$. If we differentiate $o^{2}-o^{3}$ and set the result to zero, we receive $20-3 \mathrm{o}^{2}=0$. The non-trivial prediction that can be obtained from this example is $\mathrm{o}=2 / 3$ or 0.67 .

\section{Saliency}

A further source of bargaining power can be the saliency that an actor attaches to a negotiation. Keohane and Nye were the first to observe that 'asymmetric interdependence' shapes international bargaining

40. Hirschman, National Power; Knight, Institutions and Social Conflict; Knorr, Klaus, 'International Economic Leverage and its Uses', in Economic Issues and National Security, Klaus Knorr and Frank Trager (eds.), Lawrence, Kansas: University of Kansas Press, 1977, 99-126.

41. Hirschman, National, 45.

42. Richard E. Kihlstrom, Alvin E. Roth, and David Schmeidler, 'Risk Aversion and Solutions to Nash's Bargaining Problem', in Game Theory and Mathematical Economics, eds. Otto Moeschlin and Diethard Pallaschke (Amsterdam: North Holland, 1981), 65-71. 
outcomes: Countries that are highly integrated and consequently more intensively interested in the conclusion of an agreement will, in their view, make larger concessions. ${ }^{43}$ Commenting in a similar vein upon the utility of EU membership, Moravscik and Vachudova write: 'The applicants are forced into concessions precisely because the basic benefit offered to them - membership - is of such great value' ${ }^{44}$ The hypothesis that economic interdependence is an indirect bargaining tool has provoked some criticism. Most notably, Wagner has remarked that there is no guarantee that varying saliences directly translate into an advantage during the negotiations: 'asymmetrical economic interdependence does not imply that one bargainer will be able to exercise political influence over another' ${ }^{\prime 4}$ Banks has deduced from his generalised crisis bargaining game an argument that is similar to the Keohane and Nye prediction. Interestingly, he further demonstrates that leveraging bargaining power can lead to an extreme tradeoff between the risk of breakdown and the division of the spoils: '"stronger" countries (i.e., those with greater expected benefits from war) are more likely to end up in a war; yet if the bargaining negotiations are successful and war is averted, stronger countries receive a better settlement as well' ${ }^{46}$ Here, I operationalise the saliency that a negotiator attaches to a topic formally as a multiplicative factor of the individual actor's utility function.

(3) $\max _{O \in \Theta_{i=1}} \prod_{i}^{n} s_{i}\left(u_{i}(O)-u_{i}(Q)\right)^{i} \quad$ where $\quad s_{i}=e_{i}+o_{i}$

The results that we will calculate indicate that the concessions of a negotiator depend on the concession $\mathrm{o}_{i}$ and the relative interest $e_{i}$ that

43. Keohane and Nye.

44. Moravcsik and Vachudova, 'National Interests, State Power', 49.

45. R. Harrison Wagner, 'Economic Interdependence, Bargaining Power, and Political Influence', International Organization 42 (1988): 461-83.

46. Jeffrey S. Banks, 'Equilibrium Behavior in Crisis Bargaining Games', American Journal of Political Science 34 (1990): 599-614, 600. The positive correlation that Banks established between the utility of war and the probability of a violent outcome justifies the monotonicity assumption in expected utility models of war and in non-cooperative models that B. Bueno de Mesquita has used for predictive purposes. These models can not, however, be tested because their source code is not known to the author. For an introduction to this approach, see Bruce Bueno de Mesquita, Predicting Politics (Columbus, OH: Ohio State University Press, 2002). 
an actor attaches to a proposal; a justification for this operationalisation will be given later. Assume first that $\mathrm{e}_{\mathrm{i}}=1$ and $(1+\mathrm{o}) \mathrm{o}(\mathrm{o}-1)$, which leads to $1-3 \mathrm{o}^{2}$ or $\mathrm{o}^{2}=1 / 3 \approx 0.57$. If we double the relative interest of actor $\mathrm{i}$ to $\mathrm{e}_{\mathrm{i}}=2$, we receive the following argument $(2+o) o(1-o)$ and, after some manipulation, $2 \mathrm{o}-\mathrm{O}^{2}-\mathrm{O}^{3}$. If we differentiate this argument, we obtain 2-2o$3 \mathrm{o}^{2}=0$. The positive outcome for this calculation is $\mathrm{o}=2 / 3$. An increased salience increases in line with the Banks' conjecture the share an actor can obtain from a bargain.

In sum, the NBS can be used to illustrate how some of the implicit and explicit hypotheses in international relations theory can be translated into a bargaining context that links forms of power to the actors' success during the negotiations. The NBS particularly allows us to show how the relative attractiveness of an agreement and capabilities can influence negotiation processes. Obviously, one actor can have an attractive outside option but possess only few resources. This will most likely mean that the two influences cancel each other out. The bargaining literature thus easily demonstrates that a given bargaining power is, in itself, no panacea. The different facets of bargaining power are not quite so fungible as, for instance, security policy analysts have argued..$^{47}$ In their view, different power resources can in general be easily substituted when an actor wants to influence a given political process. Thus, Art argues '[e]conomic wealth has the highest fungibility', while other resources are stickier but can still be exchanged to achieve the same end. ${ }^{48}$ Yet, this fungibility conjecture largely rests on the implicit assumption that power always becomes effective through the same mechanism and thus the identical functional form. As my analysis shows by contrast, the substitutability of diverse resources ultimately depends on the channel through which such resources influence the bargaining behaviour of international actors. They are only fungible if they are made effective through the same causal mechanism. The necessity of specifying the functional form through which power affects the outcome of a negotiation alerts us to the need to move away from speculations about the 'nature' of power. Unless we link our theory to a precise verbal or mathematical model, our understanding of bargaining power or "power" in general - remains speculative and superficial.

The empirical problem that the formal theory of bargaining cannot solve is determining which form of capability is influential at the

47. Art.

48. Art, 15. 
bargaining table. To assess the potential impact of an actor, the realist literature most often looks at the general attributes of a state. Liberals, by contrast, also take the preferences of sub-state actors into account. The empirical comparison that I introduce below uses both kinds of indicators. I compare three models: a saliency model, an economic power model and a domestic interest model. The saliency model is the base model and includes the individual saliency of the negotiations as a weight. The economic power model adds to this the economic power of a nation as an exponential weighting factor, while the domestic interest model does the same for a measure of the saliency of the negotiation topic within a country. This means that equation (3) stands for the baseline causal mechanism and equation (2) for two additional models that only differ in the empirical content of the power measure.

Comparing the predictive accuracy of models is standard procedure in attempts to assess the explanatory power of theories. Morton has, however, convincingly shown that the translation of a theory into an empirical testing strategy is not unproblematic. ${ }^{49}$ Researchers have to be clear whether they test a full or, as in this case, a partial model. As I enrich the NBS here through considerations from other theories, I advance competing models of bargaining power that combine elements of formal and informal thinking on bargaining. Models generally ease the way in the fundamental task of translating theories and serve, as Morgan and Morrison have argued, as 'mediators' between theory and data: 'They provide us with a tool for investigation, giving the user the potential to learn about the world or about theories or both'..$^{50}$ Yet, certain problems in this process remain, most notably if a specific model requires a particular measurement strategy that is incompatible with the demands of another approach. ${ }^{51}$ However, this problem of conceptual validity does not arise in the present model comparison as all competing conceptualisations of bargaining power refer to the same analytical framework.

\section{The GATS Negotiations as an Illustration}

This section illustrates the theoretical exposition of the three bargaining power models. I will analyse how large the concessions were that 29

49. Rebecca B. Morton, Methods and Models: A Guide to the Empirical Analysis of Formal Models in Political Science (New York: Cambridge University Press, 1999).

50. Margaret Morrison and Mary S. Morgan, 'Models as Mediating Instruments', in Models as Mediators: Perspectives on Natural and Social Science, eds. Mary S. Morgan and Margaret Morrison (Cambridge: Cambridge University Press, 1999), 35.

51. Gerald Schneider, Bernard Steunenberg and Mika Widgrén, ‘Evidence With Insight: What Models Contribute to EU Research', in The European Union Decides. 
GATT member states made during the negotiations on the Uruguay round multilateral trade negotiations within the tourism sector. ${ }^{52}$ This policy area belonged to the negotiation package that ultimately resulted in the "General Agreement on Trade in Services" (GATS) which aims at removing entry barriers for foreign firms in sectors ranging from banking and insurance to telecommunications and transportation. I have selected the tourism sector because of the relative ease with which I was able to obtain proxy measures for the bargaining power of the actors and their possible disagreement value. A further consideration was the relatively large number of actors for which I was able to obtain detailed information.

Although empirical studies on multilateral trade negotiations are plentiful, the GATS negotiations have not received much academic attention despite their substantial importance..$^{53}$ An exception is the qualitative study by Chrystal..$^{54}$ Largely focusing on the role of the U.S. negotiators, Chrystal maintains that international power and domestic politics alone cannot explain the conclusion of this agreement, one must also consider the important learning effects that occurred in the negotiations: 'policy makers in the LDCs changed their policy preferences during the course of the negotiations because they came to accept the validity of certain economic principles and altered their beliefs'..$^{55}$

This paper does not attempt to include ideational factors or learning but limits its evaluation to standard bargaining arguments made in the international relations literature. As Achen convincingly argues, to test a theory does not require that we evaluate all arguments that have been made. ${ }^{56}$ On the contrary, it is preferable to test simultaneously only for a very few influences, and give them a sound theoretical foundation. It is, moreover, nearly impossible to obtain indicators that sufficiently approximate the demanding concepts advocated by social constructivism and related approaches.

52. These member states are (in alphabetic order): Australia, Austria, Belgium, Canada, Czech Republic, Denmark, Finland, France, Germany, Greece, Hungary, Iceland, Ireland, Italy, Japan, Korea, Mexico, Netherlands, New Zealand, Norway, Poland, Portugal, Slovak Republic, Spain, Sweden, Switzerland, Turkey, the United Kingdom and the United States.

53. E.g., Gordon C. Rausser, ed., GATT Negotiations and the Political Economy of Policy Reform (Berlin: Springer, 1995).

54. Jonathan Chrystal, 'Bargaining in the Negotiations over Liberalizing Trade in Services: Power, Reciprocity, and Learning', Review of International Political Economy 10, no. 3 (2003): 552-78.

55. Ibid., 558.

56. Christopher H. Achen, 'Toward a New Political Methodology: Microfoundations and ART', Annual Review of Political Science 5 (2002): 423-50. 
The research design I develop here departs from the conventional studies on bargaining success in several ways. The standard approaches to testing the influence of bargaining power in multilateral negotiations, like those for the GATS agreement, are statistical tests or comparative case studies that pit successful negotiators against less successful ones. The problem with these approaches, however, is that they do not take into account the fact that the concessions received by one actor depend upon the concessions received by the other actors. This strategic interdependence violates one general requirement of standard comparative approaches, be they quantitative or qualitative by nature. Both comparative case studies and regressions techniques assume that the cases under consideration are independent of each other. This is, however, necessarily not the case for the concessions that actors receive within one negotiation round..$^{57}$

As I focus on one negotiation package within the GATS negotiations, I will follow a research strategy that explains the concessions of an actor as a function of the concessions of the other actors. I will make use of some specialised GAUSS routines that allow the researcher to calculate different NBS models and enable her to predict the final outcome. In a standard NBS model, the predicted outcome depends on the disagreement value of all actors and the share they prefer. The share is here expressed as the size of the concessions that an actor receives relative to the other actors' concessions. To make the bargaining process non-trivial, I assume that the participating nations face a real trade off: They would like their own industry to profit from open access to other markets, but simultaneously would like to minimise their own concessions. This leads to a weighting of the difference between the actors' individual preferences and the disagreement values and implies the following utility function $\mathrm{U}_{\mathrm{i}}$ for actor i:

$$
U_{i}(O, Q, E)=\left[\left(e_{i}+o_{i}\right) \sum_{\substack{j=1 ; \\ j \neq i}}^{n-1} e_{j}\left(q_{j}-o_{j}\right)\right]^{p_{i}}
$$

\footnotetext{
57. Actor-based negotiation analysis is thus only appropriate if one is able to compare different negotiations. But even in this case, one has to consider that the gains and loses of actors within one negotiation depend upon each other. Studies that use such clustering techniques include Schneider and Baltz, 'The Power of Specialization'; Bailer, 'Bargaining Success in the European Union'; and Bailer, Macht und Verhandlungserfolg.
} 
In equation (4), $\mathrm{O}$ is the vector of the concessions that the different nations obtained, $\mathrm{Q}$ is the vector of the disagreement values, and $\mathrm{E}$ is the vector of the relative economic power of the states for which information was received. The lower case letters stand for the corresponding concepts at the actor level. The relative power of an actor for which I will introduce different measures is expressed as $p_{i}$ with $p \geq 0$.

One feature of the utility function is based on the implicit assumption that all actors will be able to gain from liberalisation. Looking at the parts of the argument divided by the sigma sign: the first defines how badly a state needs concessions and how high its current protection level is; the second summarises how many concessions actor $i$ can expect from the liberalisation of the other countries. The general expectation is that competitive countries will make more concessions, while less competitive countries will try to protect their market.

Information on the concessions is built on a content analysis of a report by the World Trade Organization which summarises in detail the final results of the negotiations. ${ }^{58}$ The indicator used is an additive index that lists the number of exemptions a country received. To make the concessions comparable with the disagreement value $Q$, I have normalised both concepts around their means. ${ }^{59} \mathrm{I}$ will measure the actor's average tariff level in 1990 as a measure for their disagreement value. ${ }^{60}$ The economic power of a country that I will use to run the capabilities model is the GDP per capita of a nation. The weighting factor $\mathrm{e}_{\mathrm{i}}$ is expressed as the national GDP per capita divided by the sum of the other nations' GDP. Finally, the domestic actor model uses the tourism expenditures in Million US dollars in 1990 divided through the population size of a country. The underlying assumption is that the importance of sectoral interests grows with the size of the tourism industry.

The exemptions that the GATT member states obtained in the end differed substantially. Table 1 shows the real outcomes and the predictive errors of the three models underquestion. As the evaluation is relational, the outcomes are the concessions a country obtained

58. World Trade Organization, The Results of the Uruguay Round (CD-ROM: Geneva: WTO, 1996).

59. The results might still partly depend on the scales in which I measured the different concepts. As the empirical evaluation is, however, nonetheless of interest, I leave sensitivity tests of the source code to further exploration.

60. The data can be found on the homepage of the WTO (http:/ / www.wto.org /english/res_e/statis_e/statis_e.htm). I have used the EU tariff level for Austria, Finland and Sweden although the completion of the Uruguay Round preceded the formal entry of these states to the European Union for some months. The tariff rates of these member states can also be found on the WTO homepage. 
divided by the mean concession. Results which compared the concessions of a country to the sum of all concessions or the maximum concession did not differ much.

Table 1: Relative Real and Predicted Concessions in the GATS Negotiations on Tourism

\begin{tabular}{lcccc} 
Country & Outcome & $\begin{array}{c}\text { Accuracy of } \\
\text { Salience } \\
\text { Model }\end{array}$ & $\begin{array}{c}\text { Accuracy of } \\
\text { Capabilities } \\
\text { Model }\end{array}$ & $\begin{array}{c}\text { Accuracy of } \\
\text { Domestic } \\
\text { Actor Model }\end{array}$ \\
\hline Australia & 1.06 & 0.55 & 0.41 & 0.71 \\
Austria & 1.70 & 1.15 & 1.02 & 0.65 \\
Belgium & 0.85 & 0.32 & 0.18 & 0.28 \\
Canada & 0.42 & 0.33 & 0.09 & 0.13 \\
Czech Republic & 2.54 & 0.28 & 0.59 & 1.12 \\
Denmark & 0.85 & 0.59 & 0.39 & 0.47 \\
Finland & 0.00 & 0.47 & 0.62 & 1.07 \\
France & 0.85 & 0.32 & 0.18 & 0.62 \\
Germany & 0.85 & 0.24 & 0.12 & 0.13 \\
Greece & 0.85 & 0.82 & 0.69 & 0.04 \\
Hungary & 0.64 & 1.63 & 1.32 & 1.81 \\
Iceland & 0.00 & 0.31 & 0.50 & 2.34 \\
Ireland & 0.85 & 0.48 & 0.42 & 0.36 \\
Italy & 1.27 & 0.64 & 0.52 & 0.87 \\
Japan & 1.27 & 1.14 & 0.90 & 1.27 \\
Korea & 0.85 & 0.98 & 0.80 & 0.18 \\
Mexico & 2.29 & 0.31 & 0.53 & 1.37 \\
Netherlands & 0.85 & 0.28 & 0.15 & 0.16 \\
New Zealand & 0.00 & 1.13 & 1.12 & 0.91 \\
Norway & 0.00 & 0.34 & 0.53 & 1.79 \\
Poland & 1.91 & 0.41 & 0.07 & 0.92 \\
Portugal & 1.27 & 0.37 & 0.24 & 0.55 \\
Slovak Republic & 2.54 & 0.28 & 0.59 & 1.12 \\
Spain & 0.85 & 0.50 & 0.44 & 0.28 \\
Sweden & 0.64 & 0.30 & 0.12 & 0.75 \\
Switzerland & 1.70 & 1.70 & 1.70 & 1.26 \\
Turkey & 1.27 & 1.04 & 0.71 & 0.30 \\
United Kindom & 0.85 & 0.05 & 0.02 & 0.08 \\
United States & 0.00 & 0.00 & 0.00 & 0.00 \\
& & & &
\end{tabular}


If we express the concessions made towards another country in a relative way and contrast it with the mean concession, we have the United States at one extreme with no concessions obtained, and the Czech and Slovak Republics at the other with concessions that were 2.5 times larger than the mean concession. This contrasting finding already shows that models that simply link the negotiation success to the size of the economy of a country cannot explain international bargaining convincingly. On the contrary, some richer states make more concessions because a market opening means more for them ${ }^{61}$ This is for instance the case for Norway, Iceland or the United States. Relatively poor countries - and especially the transition economies - by contrast, were able to protect their markets from foreign access much better than other states, apparently by advancing an 'infant industry' argument. That some rich countries, like Switzerland, which should be willing to give in according to this criterion, nonetheless upheld a protectionist regime reveals the relevance of the domestic politics model.

The domestic politics model, which includes information on the size of the tourism sector, delivers more accurate predictions for the Alpine republic. The inclusion of the GDP per capita - i.e. the capabilities - in the exponent also make a difference for some countries. For instance, in comparison to the benchmark model, the predicted concessions for Great Britain or Canada are more accurate. These results mean that the economic might of a country works two ways. A strong economy makes a country less successful in negotiations because it would be highly interested to reap the benefits of fully integrated markets. Yet, the economic power that a wealthy country can put onto the negotiation table partly counteracts this influence. Capabilities should, in other words, not be disregarded as an important channel of influence for negotiators.

Note that the partial delegation of authority in concluding multilateral trade arrangements within the European Union blurs the picture somehow. I have assumed for the models that the member states have a joint disagreement value, as the EU has a uniform outside tariff. The importance of the negotiations for these countries differs, however, considerably, as the countries vary in size and economic capacity.

To compare the relative success of the different countries against each other does not yet tell us much about the predictive accuracy of the models in general. Table 2 summarises the predictive accuracy of the three models according to two criteria: the average predictive error and the number of relatively precise forecasts. The first criterion is not innocent, however, as it favours models that forecast compromise

61. Keohane and Nye. 
solutions rather than extreme outcomes. ${ }^{62}$ This is why I also include two measures that count the number of "close" predictions; forecasts in which the error is close to zero. The first criterion that I use includes all predictions for which the error is smaller than half of the standard deviation of the model predictions; the second benchmark counts the number of predictions that are smaller than the mean error. Table 2 summarises these results.

Table 2: Predictive Accuracy of Three Models of the GATS Tourism Negotiations

\begin{tabular}{llll} 
Model & $\begin{array}{l}\text { Mean } \\
\text { Error }^{1}\end{array}$ & $\begin{array}{l}\text { Close } \\
\text { predictions I }\end{array}$ & $\begin{array}{l}\text { Close } \\
\text { predictions II }^{3}\end{array}$ \\
\hline Saliency model & $0.58(0.43)$ & 2 & 19 \\
Capabilities model & $0.52(0.41)$ & 8 & 16 \\
Domestic politics model & $0.74(0.60)$ & 13 & 16
\end{tabular}

Notes: The results refer to the concessions of the individual country in relation to the mean concession.

${ }^{1}$ Standard deviation in parentheses.

${ }^{2}$ The "level of error" is smaller than half of the standard deviation.

${ }^{3}$ The "level of error" is smaller than the mean error.

The results reported in Table 2 show that the capabilities model offers the most accurate forecasts on average, closely followed by the saliency model. The large standard deviation for the domestic politics model, however, indicates that the reliance on the mean error can be misleading. The domestic politics model offers the largest number of errors that are only half of a standard deviation away from the real outcome. Obviously, the standard deviation for this model is larger. Yet, we see that the differences between the models are not so great if we turn to the second benchmark, which assesses the number of close predictions. The baseline model, the capabilities and the domestic politics model have almost the same number of predictions for which the error is smaller than the mean error.

This reveals a certain ambiguity in the impact that domestic interests have on negotiation behaviour. While some governments have taken the interests of the tourism sector at least partially into account, others have completely disregarded the industry's preferences. This

62. Bruce Bueno de Mesquita, 'Decision Making Models, Rigor and New Puzzles', European Union Politics 5, no. 1 (2004): 125-38. See also Morton. 
leads statistically to a larger number of errors that are far away from the real outcome. If we were to remove some of the extreme outliers like those reported for Iceland or Norway, the average predictive accuracy of this model would be much better. Hence, we should not completely discount domestic politics as an explanation when we evaluate the relevance of different forms of bargaining power. Although domestic politics did not matter in the mind of the average negotiator for the case under examination, it surely influenced some governments.

A final consideration is how close the models are to each other and how often one model performs better than another one.

Table 3: Comparison of the predictive errors

Correlation Superiority ${ }^{1}$

$\begin{array}{lcl}\text { Saliency model/Capabilities model } & 0.91 & 6 / 27 \\ \text { Saliency model/Domestic politics model } & 0.26 & 15 / 28 \\ \text { Capabilities model/Domestic politics mode } & 10.46 & 20 / 28\end{array}$

Notes: The correlations are Pearson moment correlations coefficients between the errors of the predictions. Superiority stands for the number of times that the first model yields more accurate predictions than the second one. The aggregate numbers do not have to amount to the total number of countries because of ties. ${ }^{1}$ The first number stands for the number of times the first model performed better, the second one is the number of non-tied results

As Table 3 reveals, the saliency and the capabilities model are relatively similar, while the domestic politics model delivers the most original forecasts. Interestingly, the saliency model loses some of its analytical appeal if we compare the accuracy of the models for each country. The domestic politics model is, for instance, almost as precise as the baseline model. According to this criterion, the capabilities model is the most appropriate analytical tool to understand the GATS negotiations. This is a further confirmation of the traditional suspicion that capabilities are an important resource for international bargainers.

\section{Conclusion}

The main theories of international relations have, by and large, neglected to specify exactly how bargaining power affects international outcomes. This is a major shortcoming, as bargaining is certainly one of the most frequent ways in which nation states and other international actors make collective decisions. Although several scholars have started 
to model the competing theories within a bargaining context, the main advances that the bargaining theory of international relations has made have been restricted to the study of militarised conflicts. Some contributions to this field go as far as modelling the conduct of warfare as an implicit bargaining process. ${ }^{63}$

This article has addressed bargaining within another arena and presented several channels through which different forms of power such as varying saliency or capabilities affect multilateral decision making on international trade. The application of the Nash Bargaining Solution (NBS) enabled me to demonstrate the empirical relevance of the liberalist asymmetric interdependence model, which conceives the saliency of a negotiation as a major source of bargaining power. The more important a negotiation is for a country, the larger the concessions that it will make to its partners. Conversely, capabilities, the common denominator definition of bargaining power in realist models, influence an international negotiation in a different way. In the NBS, they can be modelled as an exponential weight of the utility argument, whereas saliencies enter the calculation as a multiplicative term. We can understand the impact that domestic actors have on the bargain in a similar way. ${ }^{64}$ In general, however, as the channels for the different forms of power vary, we can not assume that different forms of power can just act as easy substitutes. The diverse facets of power are, in other words, not as easily fungible as some have claimed.

In the GATS negotiation on the tourism sector, the saliency attached to an issue and the relative economic weight of a country were important power resources. The relative size of the tourism industry, by contrast, was on average unimportant although a model should not be evaluated for the accuracy of the mean prediction alone. This result underlines that negotiating governments are often shielded from domestic interests in the international arena. The fact that governments from relatively poor countries were able to obtain larger concessions gives some weight to the Schelling conjecture according to which the supposedly weak negotiators is often more successful in international negotiations. This result and some related findings presented in this paper should also alert us that lofty generalisations about the impact of power are not appropriate as long as the causal mechanism through which the actor leverages its success in the international arena is not specified. As I have stated in this paper, power is most often exerted in the international arena through bargaining. In order to explain world

63. See Powell for a discussion.

64. Stefanie Bailer and I offer a slightly different model if domestic politics in, 'Nash versus Schelling?'. 
politics, it seems mandatory to study more intensively how power affects bilateral and multilateral negotiations. Empirically grounded bargaining models like the ones presented here will continue to help us understand why some negotiators are more successful than other ones.

Gerald Schneider is Professor of Political Science in the Department of Politics and Management at the University of Konstanz, Germany 